\title{
The Effect of Elevated Basal Follicle Stimulating Hormone Levels on Assisted Reproductive Technology Cycle Outcomes
}

\author{
Inci KAHYAOGLU ${ }^{*}$, Hatice YILMAZ DOGRU² Sezin ERTURK AKSAKAL ${ }^{3}$, Iskender KAPLANOGLU ${ }^{3}$, \\ Serdar DILBAZ ${ }^{3}$, Leyla MOLLAMAHMUTOGLU ${ }^{1}$
}

Ankara, Turkey

\begin{abstract}
OBJECTIVE: Despite the availability of better biomarkers, basal day 3 follicle-stimulating hormone is widely available and often used as the first-line test in ovarian reserve evaluation. The aim of this study was to evaluate the outcomes of cycles with elevated $(>12 \mathrm{IU} / \mathrm{mL})$ basal follicle-stimulating hormone values.
\end{abstract}

STUDY DESIGN: Cycles with basal day 3 follicle-stimulating hormone values $>12 \mathrm{IU} / \mathrm{mL}$ were divided into four cohorts according to follicle-stimulating hormone levels: group I, follicle-stimulating hormone between 12-15 IU/m, group II between 15-20 IU/mL, group III between 20-25 IU/mL and group IV >25 $\mathrm{IU} / \mathrm{mL}$. Both demographic characteristics and controlled ovarian stimulation parameters were retrospectively reviewed.

RESULTS: Total antral follicle count was significantly higher in group I compared to the other three groups ( $p=0.001$ ). Number of follicles $\geq 17 \mathrm{~mm}$ on human chorionic gonadotropin (hCG) day, number of retrieved oocytes, mature oocytes and fertilized oocytes were significantly higher in group I compared to the other groups $(p=0.003, p=0.001, p=0.001$, and $p=0.001$, respectively). No significant difference was found between groups regarding cancellation rates. The rate of embryo transfer per started cycle was significantly higher in group I compared to group III and group IV $(p=0.001)$. Clinical pregnancy rates per embryo transfer were comparable among the groups.

CONCLUSION: Despite the retrieval of lower quantities of oocytes, reasonable pregnancy rates could be achieved if embryo transfer was performed in cycles with follicle-stimulating hormone values over 12 $\mathrm{IU} / \mathrm{mL}$.

Keywords: Assisted reproductive technologies, Clinical pregnancy, Follicle-stimulating hormone, Poor ovarian response,

Gynecol Obstet Reprod Med 2021;27(2):138-142

${ }^{1}$ Dr. Zekai Tahir Burak Women's Health Research and Education Hospital, Department of Obstetrics and Gynecology, Ankara, Turkey

${ }^{2}$ Gaziosmanpasa University Faculty of Medicine, Department of Obstetrics and Gynecology, Tokat, Turkey

${ }^{3}$ Etlik Zubeyde Hanım Women's Health Research and Education Hospital, Department of Obstetrics and Gynecology Ankara, Turkey

Address of Correspondence: Inci Kahyaoglu

University of Health Sciences, Zekai Tahir

Burak Women Health Care Education and

Research Hospital 06230 Ankara, Turkey

mdincikahyaoglu@gmail.com

Submitted for Publication 04.07.2019 Revised for Publication: 30.07.2019

Accepted for Publication: 13.09.2019 Online Published: 02.08.2021

ORCID IDs of the authors: $\quad$ IK: 0000-0002-2283-9128

HYD:0000-0003-3431-2072 SEA: 0000-0002-4418-7319

IK: 0000-0001-8065-5143 SD: 0000-0001-9542-2799

LM: 0000-0003-4904-3303

\begin{tabular}{|c|c|}
\hline $\begin{array}{c}\text { Quick Response Code: } \\
\text { a }\end{array}$ & Access this article online \\
\cline { 2 - 2 } & $\begin{array}{l}\text { Website: www.gorm.com.tr } \\
\text { e- mail: info@gorm.com.tr }\end{array}$ \\
\cline { 2 - 2 } & DOI:10.21613/GORM.2019.998 \\
\hline
\end{tabular}

\section{Introduction}

Major determinants of the success of assisted reproductive technologies (ART) depend on women's age and ovarian reserve, which indicate reproductive potential as a function of the number and quality of remaining oocytes (1). Despite the availability of better biomarkers of ovarian reserve such as antral follicle count (AFC) and anti-Müllerian hormone $(\mathrm{AMH})$, basal day 3 follicle-stimulating hormone (FSH) is widely available and often used as either the first-line or the only test in ovarian reserve evaluation (2). It is routinely used to determine the ovarian reserve in many ART units prior to starting ART treatment (3). Elevated basal FSH level is thought to reflect ovarian aging and is associated, at least in

How to cite this article: Kahyaoglu I. Yilmaz Dogru H. Erturk Aksakal S Kaplanoglu I. Dilbaz S. Mollamahmutoglu L. The Effect of Elevated Basal Follicle Stimulating Hormone Levels on Assisted Reproductive Technology Cycle Outcomes. Gynecol Obstet Reprod Med 2021;27(2):138-142 
older women undergoing in vitro fertilization (IVF), with poor ovarian response and low pregnancy rates $(4,5)$ and a higher chance of fetal loss (6). It is a common practice in many IVF center to defer treatment when the FSH values are high (7).

The purpose of the present study was to evaluate the success rates of ART cycles with elevated basal FSH values and to present a tool to the clinician for realistic opinion and proper consultation with the patient.

\section{Material and Method}

Medical records of patients who underwent treatment in the center of assisted reproduction of a tertiary hospital from September 2007 to December 2016 were reviewed. Cycles with basal day $3 \mathrm{FSH}$ values $>12 \mathrm{IU} / \mathrm{mL}$ were identified. All cycles were divided into four cohorts according to FSH levels: group I, FSH between 12-15 IU/mL, group II between 15-20 $\mathrm{IU} / \mathrm{mL}$, group III between $20-25 \mathrm{IU} / \mathrm{mL}$ and group IV $>25$ $\mathrm{IU} / \mathrm{mL}$. Cycles with no sperm retrieval, with FSH values $<12$ $\mathrm{IU} / \mathrm{mL}$, and frozen embryo transfer cycles were excluded from the study. The consent for using data was obtained and the study was approved by the institutional review board (21/12/2016-Number: 219). The study was performed in accordance with the Declaration of Helsinki.

Both demographic characteristics and controlled ovarian stimulation (COS) parameters were retrospectively reviewed based on patient files and the computer database. Controlled ovarian hyperstimulation was performed using long GnRH agonist, microdose flare or antagonist protocols. Either pure recombinant FSH or human menopausal gonadotropin (HMG) was used. The dose of gonadotropins was individualized according to the patient's age, baseline serum FSH concentration on day 3 and body mass index (BMI). Cycles were monitored by serial transvaginal ultrasound evaluation and serum estradiol determination. When at least three follicles reached a mean diameter of $17 \mathrm{~mm}$, final oocyte maturation was triggered with the administration of recombinant human chorionic gonadotropin (hCG) (Ovitrelle; Merck-Serono, Istanbul, Turkey) (250 mg when BMI $<29 \mathrm{~kg} / \mathrm{m}^{2}$ and $500 \mathrm{mg}$ when BMI $\left.>29 \mathrm{~kg} / \mathrm{m}^{2}\right)$.

Oocyte pick up (OPU) was performed by transvaginal ultrasound-guided aspiration 35.5-36 h after the hCG injection. As a policy of the clinic, intracytoplasmic sperm injection (ICSI) was performed for all oocytes. Signs of fertilization (presence of two pronuclei and two polar bodies) was checked 16-18 h after ICSI was performed. Embryo transfer (ET) was performed on the second, third or fifth day after ICSI.

Cycle cancellation was defined as the lack of ovarian response to stimulation (no follicular recruitment and/or inadequate serum estradiol increase), retrieval of no oocytes, total fertilization failure or developmental arrest of the embryo.
Luteal support was given by either vaginal progesterone (Crinone $8 \%$ gel, Merk, Istanbul) twice daily or vaginal progesterone plus $100 \mathrm{mg}$ intramuscular progesterone (Progestan ampul $50 \mathrm{mg} / \mathrm{mL}$ i.m., Kocak Farma, Istanbul) from ET to the pregnancy test. A pregnancy test was performed 12 days following ET and clinical pregnancy was defined as the presence of a gestational sac with accompanying fetal heartbeat by ultrasound 4 weeks following the ET procedure.

Statistical analysis was performed using IBM SPSS Statistics Software (20.0, SPSS Inc., Chicago, IL, USA). Kolmogorov-Smirnov test was used to test the distribution of variables. Analysis of variance (ANOVA) test was used for multiple comparisons. Post-hoc analysis was done using Tukey's HSD test. Data are presented as mean \pm standard error (SE). Statistical significance was assumed with a probability error of $p<0.05$.

\section{Results}

A total of 393 cycles with basal day 3 FSH values $>12$ $\mathrm{IU} / \mathrm{mL}$ were selected for the study; 179 cycles in group I, 116 cycles in group II and 44 and 54 were in group III and group IV, respectively. Mean basal FSH levels in groups I, II, III, and IV were $13.3 \pm 0.8,17.4 \pm 1.5,22.2 \pm 1.4$, and $31.4 \pm 6.1$ $\mathrm{IU} / \mathrm{mL}$, respectively.

There were no statistically significant differences regarding female age and duration of infertility. Total AFC was significantly higher in group I compared to the other three groups ( $p=0.001)$. Total gonadotropin dose was comparable among groups $(p=0.328)$. The duration of stimulation was significantly shorter in group IV compared to the other three groups ( $p=0.034$ ). The number of follicles $\geq 17 \mathrm{~mm}$ on hCG day, number of retrieved oocytes, mature oocytes, and fertilized oocytes were significantly higher in group I compared to the other groups $(p=0.003, p=0.001, p=0.001$, and $p=0.001$, respectively) (Table I).

Regarding cancellation rates, although there was no difference among groups $(p=0.056)$, there was a tendency towards decreased cancellation rates with lower basal FSH values. The rate of ET per started cycle was significantly higher in group I compared to group III and group IV $(p=0.001)$. However, rates of clinical pregnancy per ET were comparable among the groups $(p=0.615)$ (Table II).

ROC curve analysis revealed an FSH threshold value of $15.85 \mathrm{IU} / \mathrm{mL}$ with $52.5 \%$ sensitivity and $66.7 \%$ specificity for prediction of pregnancy (AUC 0.61) (Figure 1) and a threshold value of $15.22 \mathrm{IU} / \mathrm{mL}$ with $55.1 \%$ sensitivity and $67.6 \%$ specificity for prediction of clinical pregnancy (AUC 0.60) (Figure 2). 
Table I: Demographic characteristics and controlled ovarian stimulation parameters of the cycles

\begin{tabular}{|c|c|c|c|c|c|}
\hline & $\begin{array}{l}\text { FSH } 12-15 \mathrm{IU} / \mathrm{mL} \\
(\mathrm{n}=179)\end{array}$ & $\begin{array}{l}\text { FSH } 15-20 \mathrm{IU} / \mathrm{mL} \\
(n=116)\end{array}$ & $\begin{array}{l}\text { FSH } 20-25 \mathrm{IU} / \mathrm{mL} \\
(\mathrm{n}=44)\end{array}$ & $\begin{array}{l}\mathrm{FSH}>25 \mathrm{IU} / \mathrm{mL} \\
(\mathrm{n}=54)\end{array}$ & $p$ value \\
\hline Female age (years) & $34.23 \pm 5.93$ & $35.26 \pm 5.12$ & $33.77 \pm 6.06$ & $34 \pm 5.79$ & 0.316 \\
\hline BMI $\left(\mathrm{kg} / \mathrm{m}^{2}\right)$ & $25.86 \pm 4.86$ & $26.03 \pm 4.3$ & $25.29 \pm 4.15$ & $23.67 \pm 3.81$ & 0.015 \\
\hline Total AFC & $6.01 \pm 3.7$ & $4.53 \pm 3.02$ & $3.83 \pm 2.49$ & $4.46 \pm 4.16$ & 0.001 \\
\hline Duration of infertility (months) & $69.47 \pm 61.74$ & $67.24 \pm 67.79$ & $70.93 \pm 71.12$ & $46.09 \pm 47.58$ & 0.107 \\
\hline Duration of stimulation (days) & $9.27 \pm 2.75$ & $9.23 \pm 2.8$ & $8.25 \pm 3.34$ & $8.21 \pm 3.52$ & 0.034 \\
\hline Total dose of gonadotropin (IU) & $3143.96 \pm 1323.69$ & $3094.47 \pm 1235$ & $3086.27 \pm 1295.62$ & $2751.42 \pm 1756$ & 0.328 \\
\hline Number of follicles $\geq 17 \mathrm{~mm}$ on hCG day & $1.96 \pm 1.59$ & $1.35 \pm 1.09$ & $1.43 \pm 2.51$ & $1.51 \pm 1.07$ & 0.003 \\
\hline Number of retrieved oocytes & $5.92 \pm 4.5$ & $4.27 \pm 2.89$ & $3.25 \pm 3.38$ & $2.65 \pm 2.8$ & 0.001 \\
\hline Number of mature oocytes & $4.63 \pm 3.68$ & $2.83 \pm 2.44$ & $1.75 \pm 2.36$ & $1.53 \pm 2.01$ & 0.001 \\
\hline Number of fertilized oocytes & $2.35 \pm 2.09$ & $1.4 \pm 1.84$ & $0.91 \pm 0.92$ & $1.03 \pm 1.77$ & 0.001 \\
\hline
\end{tabular}

FSH, follicle-stimulating hormone; BMI, body mass index; AFC, antral follicle count; hCG, human chorionic gonadotropin.

Table II: Outcomes of the cycles.

\begin{tabular}{|c|c|c|c|c|c|}
\hline & $\begin{array}{l}\text { FSH } 12-15 \mathrm{IU} / \mathrm{mL} \\
(\mathrm{n}=179)\end{array}$ & $\begin{array}{l}\text { FSH } 15-20 \mathrm{IU} / \mathrm{mL} \\
(\mathrm{n}=116)\end{array}$ & $\begin{array}{l}\text { FSH } 20-25 \quad \mathrm{IU} / \mathrm{mL} \\
(\mathrm{n}=44)\end{array}$ & $\begin{array}{l}\mathrm{FSH}>25 \\
(\mathrm{n}=54)\end{array}$ & IU/mLp value \\
\hline Cycle cancellation rates (\%) & 17.7 & 26.9 & 35.7 & 25.5 & 0.056 \\
\hline ET/started cycle (\%) & 55.3 & 42.2 & 20.5 & 37.0 & 0.001 \\
\hline Clinical pregnancy/ET (\%) & 24.2 & 18.4 & 11.1 & 15.0 & 0.615 \\
\hline
\end{tabular}

FSH: Follicle-stimulating hormone, ET: Embryo transfer

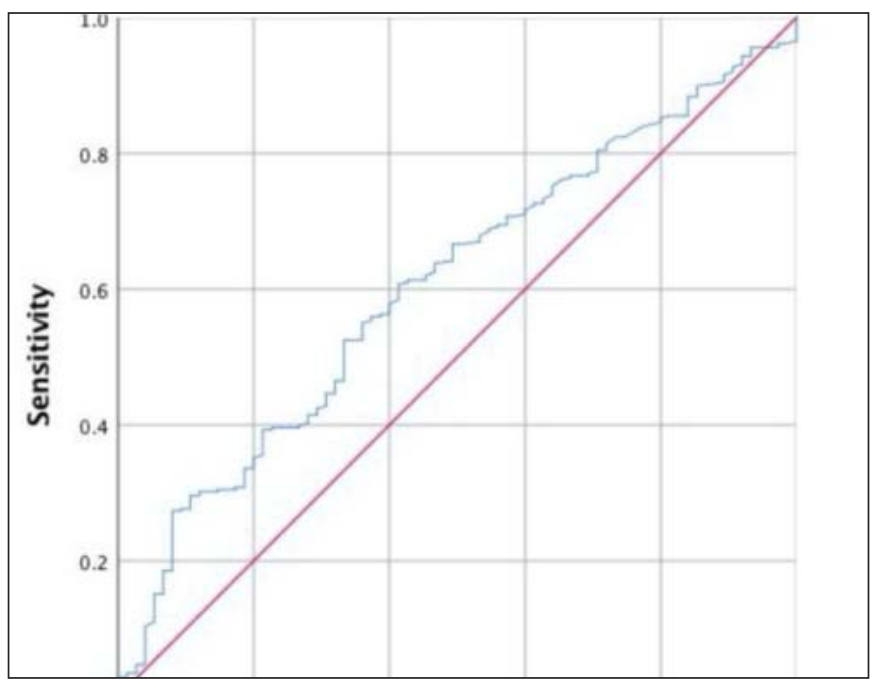

Figure 1: Receiver-operator curve analysis for the performance of basal serum follicle-stimulating hormone in the prediction of pregnancy.

\section{Discussion}

In this retrospective study, we assessed the effect of elevated basal FSH value $(>12 \mathrm{IU} / \mathrm{mL})$ on controlled ovarian stimulation parameters and cycle outcomes. Our results revealed that the number of retrieved oocytes, mature oocytes, and fertilized oocytes decreased with increasing FSH values. Also, the number of embryo transfer cycles decreased significantly with FSH values over 20 IU/L. However, when an em-

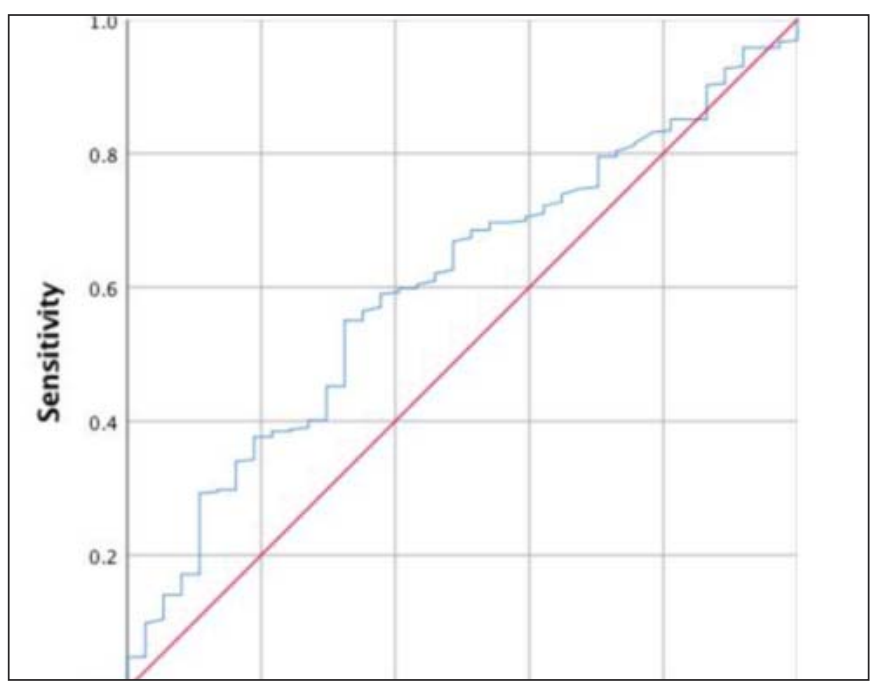

Figure 2: Receiver-operator curve analysis for the performance of basal serum follicle-stimulating hormone in the prediction of clinical pregnancy.

bryo developed and was transferred, clinical pregnancy rates per transfer seemed not to be affected by the FSH values.

Decreased ovarian reserve is a rather common problem among subfertile women, with approximately $31 \%$ of ART cycles using fresh non-donor eggs or embryos reported by the Society of Assisted Reproductive Technology being complicated by a diminished ovarian reserve in 2015 (8). The inverse relationship between elevated early follicular phase FSH and 
the diminished ovarian reserve is universally accepted (9). Several studies demonstrated that high day-3 basal concentrations of FSH are associated with a low response to ovarian stimulation, high cancellation rates, and a low chance of success in patients undergoing ART treatment $(4,5,10)$. Thum et al. compared the results of 1368 patients with normal basal FSH $\leq 10$ IU/L with 492 patients with high basal FSH $(>10$ $\mathrm{IU} / \mathrm{L})$. The average number of oocytes retrieved was lower among women with elevated FSH $(10.12 \pm 5.6$ vs $6.16 \pm 3.9)$ (9). In another study, Kojima et al. demonstrated a higher number of retrieved oocytes, fertilized oocytes and transferred embryos in patients with FSH values $<10$ IU/L $(8.7 \pm 6.1,4.6 \pm$ 3.9 , and $1.8 \pm 0.8$, respectively) compared to patients with FSH values $<15 \mathrm{IU} / \mathrm{L}(2.2 \pm 2.0,1.4 \pm 2.0$, and $0.9 \pm 0.7$, respectively, $p<0.001$ ) (3). The results of our study were in line with the mentioned studies, demonstrating decreased oocyte yield with increasing FSH levels.

However, the link between elevated FSH values and quality of the resultant embryos is a matter of debate, unlike the decreased number of oocytes retrieved. Various authors have suggested a negative effect of elevated FSH on embryonic quality and outcome of ART (11-13). However, other reports have suggested that the basal FSH level was useful as an indicator of a quantitative rather than qualitative ovarian response for ovarian hyperstimulation, meaning basal FSH level did not reflect on the quality of the oocytes $(14,15)$. Abdalla and Thum analyzed 3401 cycles of four groups divided according to FSH levels: group A, FSH $<10 \mathrm{IU} / \mathrm{mL}$, group B, 10.1-15 $\mathrm{IU} / \mathrm{mL}$, group $\mathrm{C}, 15.1-20 \mathrm{IU} / \mathrm{mL}$, and group $\mathrm{D}, \mathrm{FSH}>20$ $\mathrm{IU} / \mathrm{mL}$. In patients aged $<38$, the pregnancy rate and live birth rate were reduced, though not significantly, as FSH levels increased. A live birth rate of at least $20 \%$ was always achieved in patients with FSH between 10 and $20 \mathrm{IU} / 1$, and 16.7\% in patients with FSH $>20 \mathrm{IU} / 1$ (15). Another study by the same group also showed that women with elevated serum FSH levels had lower numbers of oocytes retrieved and lower clinical pregnancy rates compared to women with FSH levels in the normal range. However, women with an elevated basal FSH level who responded well to gonadotropin stimulation and generated a good number of oocytes/embryos had similar chances of becoming pregnant and having a live birth as women in the same age range with normal levels of FSH (9). The results of our study also demonstrated comparable clinical pregnancy rates per ET among the four groups, despite the retrieval of a decreasing number of retrieved oocytes with increasing FSH values, which was in line with the above-mentioned studies. The mean age of the patients in our study was approximately 35 in all groups. It could be hypothesized from these results that a proportion of these patients with elevated basal FSH who reach the embryo transfer stage of the treatment may have a chance of pregnancy. Increased basal FSH levels should not discourage women from attempting a cycle of IVF.
The study is not without limitations. Retrospective nature and small sample size were the main limitations of the study. Despite these limitations, comparison of groups demonstrates us the importance of the reaching of embryo transfer stage in patients with high FSH values.

In conclusion, the results of this study suggest that high basal FSH levels should not be the sole indication for withholding treatment. Despite the retrieval of lower quantities of oocytes, reasonable pregnancy rates could be achieved if embryo transfer could be performed.

Declaration of Interest: The authors declare that they have no conflict of interest.

Acknowledgment: None

Funding: None

Author Contributions: All authors contributed significantly to this study and are in agreement with the content of the manuscript, approved the final version of the paper. Concept and design of the study: I. Kahyaoglu, Data Collection and/or processing: I. Kahyaoglu, HYD, SEA. IK. LM, Literature review: I.Kahyaoglu, HYD. SEA. IK. SD. LM. Writing: I. Kahyaoglu, HYD. Critical Review: I. Kahyaoglu, HYD. SD.

\section{References}

1. Practice Committee of the American Society for Reproductive Medicine. Testing and interpreting measures of ovarian reserve: a committee opinion. Fertil Steril. 2015;103(3):e9-e17. doi: 10.1016/j.fertnstert. 2014. 12.093 .

2. Souter I, Dimitriadis I, Baltagi LM, Meeker JD, Petrozza JC. Elevated day 3 follicle-stimulating hormone in younger women: is gonadotropin stimulation/intrauterine insemination a good option? Am J Obstet Gynecol. 2014; 211(1):62.e1-8. doi: 10.1016/j.ajog.2014.01.031.

3. Kojima R, Nakagawa K, Nakashima A, Horikawa T, Ohgi $\mathrm{S}$, Saito H. Elevated basal FSH levels, if it is under 15 IU/L, will not reflect poor ART outcomes. J Assist Reprod Genet. 2008;25(2-3):73-7. doi: 10.1007/s10815-0079195-9.

4. Scott RT, Toner JP, Muasher SJ, Oehninger S, Robinson S, Rosenwaks Z. Follicle stimulating hormone levels on cycle day 3 are predictive of an in vitro fertilization outcome. Fertil Steril. 1989;51(4):651-4. doi: 10.1016/s00 15-0282(16)60615-5.

5. Toner JP, Philput CB, Jones GS, Muasher SJ. Basal follicle-stimulating hormone level is a better predictor of in vitro fertilization performance than age. Fertil Steril. 1991;55(4):784-91. doi: 10.1016/s0015-0282(16)54249-6.

6. Trout SW, Seifer DB. Do women with unexplained recurrent pregnancy loss have higher day 3 serum FSH and estradiol values? Fertil Steril. 2000;74(2):335-7. doi: 10. 1016/s0015-0282(00)00625-7.

7. Maman E, Baum M, Machtinger R, Seidman DS, Dor J, 
Hourvitz A. IVF treatment should not be postponed for patients with high basal FSH concentrations. Reprod Biomed Online. 2010;21(5):631-5. doi: 10.1016/j.rbmo. 2010.05.013.

8. Centers for Disease Control and Prevention, American Society for Reproductive Medicine, Society for Assisted Reproductive Technology. 2015 Assisted Reproductive Technology National Summary Report. Atlanta (GA): US Dept of Health and Human Services; 2017 available at https://www.cdc.gov/art/pdf/2015-report/ART-2015National-Summary-Report.pdf\#page $=14$ (Accessed on 02/06/2019).

9. Thum MY, Kalu E, Abdalla H. Elevated basal FSH and embryo quality: lessons from extended culture embryos: raised FSH and blastocyst quality. J Assist Reprod Genet. 2009;26(6):313-8. doi: 10.1007/s10815-009-9313-y.

10. Sharif K, Elgendy M, Lashen H, Afnan M. Age and basal follicle stimulating hormone as predictors of in vitro fertilisation outcome. Br J Obstet Gynaecol. 1998;105(1): 107-12.x. doi: 10.1111/j.1471-0528.1998.tb09360.x.

11. Scott RT Jr, Hofmann GE. Prognostic assessment of ovar- ian reserve. Fertil Steril. 1995;63(1):1-11. PMID: 78058 95.

12. Balasch J, Creus M, Fabregues F, Carmona F, Casamitjana R, Ascaso C, et al. Inhibin, follicle-stimulating hormone, and age as predictors of ovarian response in in-vitro fertilisation cycles stimulated with gonadotrophin-releasing hormone agonist-gonadotrophin treatment. Am J Obstet Gynecol. 1996;175(5):1226-30. doi: 10.1016/s0002-9378(96)70032-7.

13. Barnhart K, Osheroff J. Follicle stimulating hormone as a predictor of fertility. Curr Opin Obstet Gynecol. 1998; 10(3):227-32. doi: 10.1016/s0015-0282(02)04839-2.

14. van Rooij IA, Bancsi LF, Broekmans FJ, Looman CW, Habbema JD, te Velde ER. Women older than 40 years of age and those with elevated follicle-stimulating hormone levels differ in poor response rate and embryo quality in in vitro fertilization. Fertil Steril. 2003;79(3):482-8.

15. Abdalla H, Thum MY. An elevated basal FSH reflects a quantitative rather than qualitative decline of the ovarian reserve. Hum Reprod. 2004;-19(4):893-8. doi: 10.1093/ humrep/deh141. 